Check for updates

Cite this: RSC Adv., 2017, 7, 55653

Received 26th September 2017 Accepted 3rd December 2017

DOI: 10.1039/c7ra10633e

rsc.li/rsc-advances

\section{Insights into energy-efficient and eco-friendly sealing of anodic aluminum oxide film holes with alkaline earth metal salts $\uparrow$}

\author{
Hongyang Wei, ${ }^{a}$ Dongchu Chen, ${ }^{\star a}$ Huawen Hu, (D) *a Menglei Chang, ${ }^{\text {a }}$ Xiufang Ye \\ and Meifeng Wang ${ }^{b}$
}

In this study, the impact of various sealing conditions on the quality of the sealed anodic aluminum oxide (AAO) film is systematically investigated, which leads us to gain insights into sealing the AAO film. To this end, magnesium acetate and calcium acetate are employed as the main compositions of the sealant. It is demonstrated that the temperature exerts the greatest influence on the quality of the sealed film based on the weight loss and antistaining adsorption evaluations among the other examined conditions, followed by $\mathrm{pH}$, mixed salts, surfactants, and complexants. For the optimized sample, the minima of the staining level and weight-loss ratio can reach 0 and $13.4 \mathrm{mg} \mathrm{dm}^{-2}$, respectively, meeting the requirement of the ISO standard. This work also realizes an energy-efficient sealing of the AAO film at intermediate temperatures $\left(75-85^{\circ} \mathrm{C}\right)$. The potentiodynamic scanning and electrochemical impedance spectroscopy measurements reveal that the AAO film sealed by the alkaline earth metal salt possesses a superior corrosion resistance as compared to the one sealed by the conventional nickel salt. Additionally, the potential can be stable in a faster way at higher temperatures over the range of $70-$ $85^{\circ} \mathrm{C}$, as demonstrated in the $E-t$ curve. On the other hand, the potential stabilization is more readily achieved at higher $\mathrm{pH}$ values within the range of $5-7$, whereas it cannot be realized at $\mathrm{pH}$ values above 7. We also note that the appropriate addition of surfactant, complexant and $\mathrm{pH}$ buffer can assist in stabilizing the potential. In the absence of any surfactants and complexants, the potential stabilization cannot be reached. Furthermore, the present study discusses the mechanism underlying the effective sealing, thereby paving the way for the future exploration of the energy-efficient and eco-friendly sealing technologies for many practical AAO-based applications.

\section{Introduction}

As one of the largest categories of metallic materials, aluminum and its alloys have been used extensively in the scientific and engineering communities. ${ }^{1}$ This can be attributed to their light weight, high specific strength, and superior physicochemical properties..$^{1, e-g}$ Generally, before practical applications of the aluminum and its alloys, it is of technical importance and significance to form an oxidation film (with a certain thickness) on their surface for the purpose of protection from external physical and chemical corrosions, especially the anodic aluminum oxidation (AAO) film, as the focus of wide concern and generated by electrochemistry. ${ }^{1, h, h, 2}$ However, the formed AAO film possesses a large quantity of micropores ${ }^{3}$ that

${ }^{a}$ School of Material Science and Energy Engineering, Foshan University, Foshan 528000, Guangdong, China.E-mail: cdcever@163.com; huawenhu@126.com

${ }^{b}$ School of Material Science and Engineering, Nanchang Hangkong University, Nanchang 330063, China

$\dagger$ Electronic supplementary information (ESI) available. See DOI: $10.1039 / \mathrm{c} 7 \mathrm{ra} 10633 \mathrm{e}$ facilitate the corrosion media to diffuse through it and then to contact with aluminum substrate, causing the corrosion of aluminum alloys. Moreover, microporous oxidation film is ready to be contaminated due to a micropore adsorption effect. ${ }^{4}$ As a consequence, it is highly desirable to appropriately seal the micropores of the oxidation film. ${ }^{5}$ Many hole sealing methods have thus been explored, primarily including boiling water (steam), nickel salts, and polymer resins-based sealing. ${ }^{6}$ However, some obvious defects of these sealing methods seriously limit their widespread applications, such as (i) high energy consumption and low sealing quality as for the steambased sealing, (ii) strong toxicity of nickel salts which pose serious threats to the environment and humans regarding the nickel slat-based sealing, and (iii) a strong barrier for diffusion of the larger polymer molecules into the interior of the oxidation film, in addition to the unwanted change of the surface properties of the oxidation film after the polymer resin-based sealing, thus debasing the sealing effect. ${ }^{1 a, 6 a, b}$

In these regards, there is a pressing need to develop an energy-efficient, eco-friendly, and highly corrosion-resistant sealing method. Actually, many attempts have been made to 
fill the micropores of the AAO film using different kinds of rare earth compositions by immersing the rare earth metal salts into the anodic oxidation solution, ${ }^{7}$ but such a direct immersion is not able to incorporate the rare earth metal compositions into the interior of the AAO film pores. ${ }^{7 b}$ Alternatively, hole sealing of the AAO film is also realized by chemical treatment and electrochemical deposition processing of the porous structure. ${ }^{8}$ Nevertheless, only a mediocre sealing quality and hence a moderate corrosion resistance can be usually obtained, indicating that further efforts are required to improve the sealing quality relative to that achieved by many conventional sealing methods.

The hole sealing of AAO films based on alkaline earth metal salts lies in using alkaline metal salts or alkaline earth metal salts as the main compositions of the sealant. Such a sealing method is environmentally friendly and costefficient. A number of studies have been reported on the hole sealing of AAO films based on alkaline earth metal salts, ${ }^{1 c, d, b b}$ but the sealing mechanism has not been explored by far, with the focus primarily on obtaining high-quality sealed AAO films. Therefore, in this study, magnesium acetate and calcium acetate are adopted as the main composition of the sealant for sealing the holes of the AAO film. The sealing condition is systematically investigated, so as to unravel the mechanism underlying the effective sealing of the AAO film. The sealing quality is evaluated on the basis of the antistaining adsorption and weight loss tests. Not only does this study find the best conditions for high-quality sealing of the AAO film, but it also puts forward the mechanism underlying the effective sealing.

\section{Results and discussion}

\section{Optimization of the sealing formulation based on nickel-free alkaline earth metal salts}

Fig. 1a shows the antistaining effect of the prepared samples 116. Before the staining treatment with the blue colorant (with the international color no. 69\#), the sample surface was cleaned and dried. Then, the samples were immersed into the colorant for $1 \mathrm{~min}$, followed by thoroughly scrubbing for $20 \mathrm{~s}$ with a cotton fabric that had been dipped in a suspension of magnesium oxide. Upon extensively washing and drying, the stained samples were finally obtained, as presented in the following Fig. 1. The antistaining adsorption test is one of the methods for evaluating the sealing quality of the AAO film. From Fig. 1, it can be noted that the samples 1, 8 and 12 exhibit an apparent remnant color after scrubbing the stained region, revealing a strong adsorption power of the AAO film and hence an ineffective antistaining adsorption ability. In contrast, after scrubbing the stained surface, the samples $6,7,10,11,14,15$ and 16 show a shallow remnant color, indicative of good antistaining adsorption ability. Impressively, the samples 2, 3, 4, 5, 9 and 13 display the best antistaining adsorption effect, as judged by the almost indistinguishable colored region after scrubbing the stained surface. The antistaining adsorption effect of the stained samples is evaluated according to the ISO2143:2010 standard, with comparison histograms presented in Fig. 2a. From Fig. 2a, staining level 0 can be noticed for the samples 2, 3, 4, 5, 9 and 13, while level 1 can be assigned to the samples $6,7,10,11,14,15$ and 16 . The samples 8 and 12 reach level 2 of staining. The lowest level 3 is found for the sample 1 .

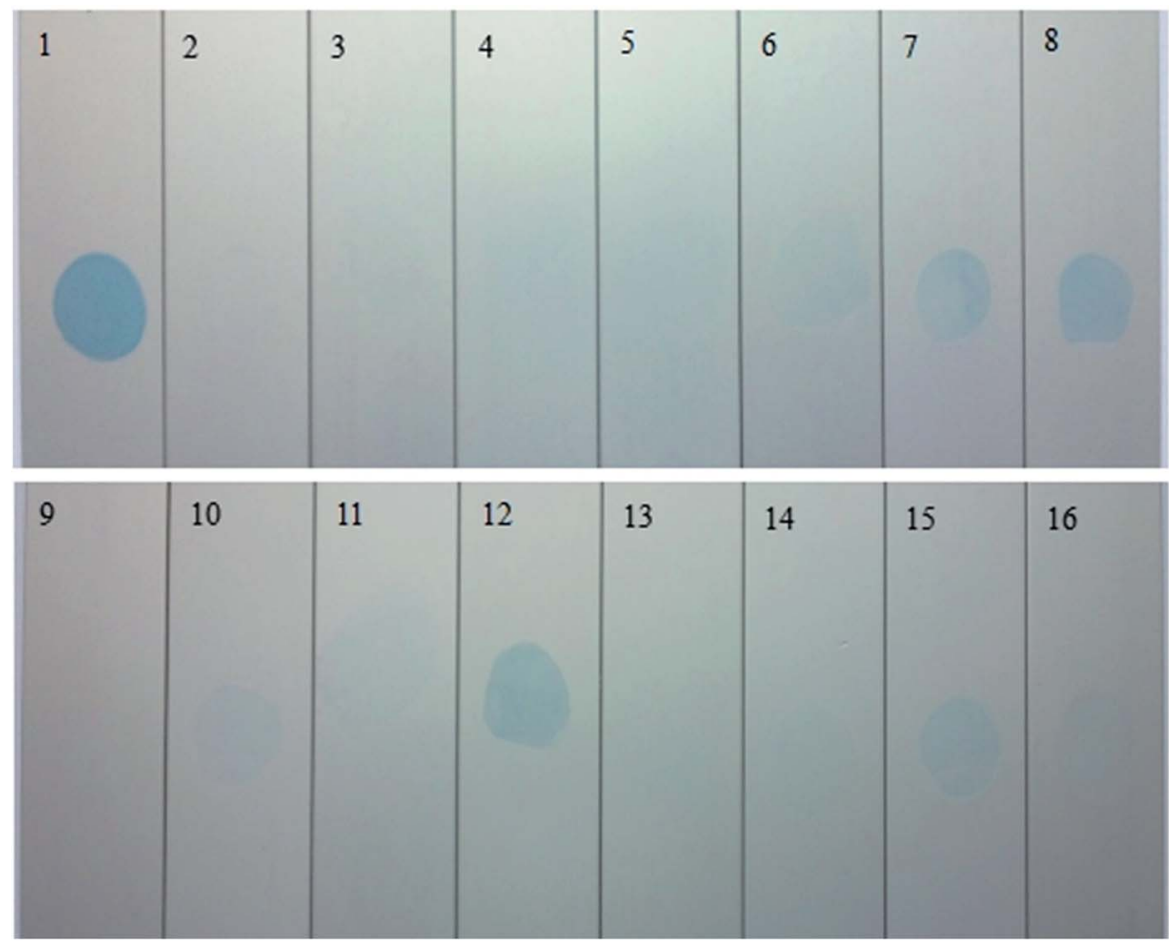

Fig. 1 The antistaining test results for the prepared samples 1-16. 
The lower the staining level, the stronger the antistaining adsorption ability. This indicates that the staining level 0 or 1 is corresponding to strong antistaining adsorption ability of the sealed samples that thereby possessing a superior sealing quality.

Apart from the antistaining adsorption evaluation, this study also adopted the weight loss test to further evaluate the sealing quality of the samples 1-16, with the results given in Fig. $2 \mathrm{~b}$. According to the ISO3210:19835 standard, the samples with the weight loss of below $30 \mathrm{mg} \mathrm{dm}^{-2}$ are qualified. It can be noted that the samples $4,5,6,9,11$, and 16 exhibit a weight loss smaller than $30 \mathrm{mg} \mathrm{dm}^{-2}$, revealing a qualified sealing. The remaining samples have an excessive weight loss, implying a poor anticorrosion performance and a low sealing quality. For the samples $4,5,6,9,11$, and 16 , the weight loss values are estimated as 19.2, 13.4, 23.4, 29.4, 13.5 and $28.9 \mathrm{mg} \mathrm{dm}^{-2}$, respectively. The smaller the weight loss value, the higher the sealing quality. The samples $4,5,6,9,11$ and 16 also possess the satisfactory staining level of 0 or 1 (Fig. 2a), thus indicating that weight loss test results are in great consistence with that of the antistaining adsorption test. In this study, the influence of


Fig. 2 Evaluation of the sealing quality for various samples based on the antistaining adsorption (a) and weight loss test (b). various hole sealing conditions is also systematically investigated through the weight lost test, including the concentrations of the salt mixture, complexant and surfactant, and $\mathrm{pH}$ and temperature, as shown in Fig. 3. The variance analysis of the weight loss index is also done (see Table 2).

From Fig. 3, it can be noted that the weight loss is initially increased and then decreased with raising the contents of the mixed salts; the lowest weight loss value is found at the $10 \mathrm{~g} \mathrm{~L}^{-1}$ content. The weight loss value is lowered first and becomes increased with the increase of the complexant content; the minimum value of the weight loss can be noted at $16 \mathrm{~g} \mathrm{~L}^{-1}$. For the impact of the surfactant, the weight loss mean value is initially lowered and consequently raised as the content of the surfactant increases, with the lowest weight loss value at $0.5 \mathrm{~g}$ $\mathrm{L}^{-1}$. Concerning $\mathrm{pH}$ influence, the weight loss value is decreased first and become raised as the $\mathrm{pH}$ rises, with the smallest weight loss value found at $\mathrm{pH}$ 7. The temperature linearly affects the weight loss values; the higher the temperature, the smaller the weight loss value. The minimum value of the weight loss is achieved at $85{ }^{\circ} \mathrm{C}$. The optimized formulation and technological conditions are given as follows: $10 \mathrm{~g} \mathrm{~L}^{-1}$ mixed salts $\left(\mathrm{Ca}\left(\mathrm{CH}_{3} \mathrm{COO}\right)_{2} \cdot \mathrm{H}_{2} \mathrm{O}, \mathrm{C}_{4} \mathrm{H}_{6} \mathrm{O}_{4} \mathrm{Mg} \cdot 4 \mathrm{H}_{2} \mathrm{O}\right), 16 \mathrm{~g} \mathrm{\textrm {L } ^ { - 1 }}$ complexant $\left(\mathrm{C}_{6} \mathrm{H}_{15} \mathrm{NO}_{3}\right), 0.5 \mathrm{~g} \mathrm{~L}^{-1}$ surfactant $\left(\mathrm{C}_{24} \mathrm{H}_{32} \mathrm{O}_{7} \mathrm{~S}_{2} \mathrm{Na}_{2}\right)$, $2 \mathrm{~g} \mathrm{~L}^{-1} \mathrm{pH}$ buffer $\left(\mathrm{CH}_{3} \mathrm{COONH}_{4}\right)$, and at $\mathrm{pH} 7$ and $85{ }^{\circ} \mathrm{C}$. The variance analysis, as shown Table 2, reveals that the order of significance of experimental conditions on the basis of weight loss test of the sealed samples is given as follows: temperature > $\mathrm{pH}>$ conc. of mixed salts $>$ conc. of surfactant $>$ conc. of complexant.

\section{Electrochemical analysis}

Potentiodynamic scanning and electrochemical impedance spectroscopy (EIS) measurements were performed on the sealed samples for carrying out the electrochemical analysis. The sealing of the AAO-based samples was conducted in the optimized liquids of the nickel-free alkaline earth metal salt and conventional nickel salt (as a control).

(a) Potentiodynamic scanning analysis. The potentiodynamic scanning measurements of the samples sealed by nickel-free alkaline earth metal salt and by the conventional nickel salt were conducted in a $3.5 \% \mathrm{NaCl}$ solution. The polarization curves shown in Fig. 4 were measured after immersing the samples in a $3.5 \% \mathrm{NaCl}$ solution for $6 \mathrm{~h}$. The self-corrosion potentials $E_{\text {corr }}$ of all the samples sealed by the alkaline earth metal salt are higher than those of the counterparts sealed by the conventional nickel salt, suggesting a lower self-corrosion tendency of the former. Table 3 presents electrochemical parameters after the Tafel curve fitting. The self-corrosion current density $I_{\text {corr }}$ as for all the sealed samples locates at the level of $10^{-9}$; this indicates that the samples sealed by both alkaline earth metal salts and nickel salts exhibit a high corrosion resistance and hence that both sealants can exert a good sealing effect on the AAO film. Under $\mathrm{pH} 7$ conditions, the self-corrosion current density as for the samples sealed by alkaline earth metal salt $\left(1.9788 \times 10^{-9} \mathrm{~A} \mathrm{~cm}^{-2}\right)$ is lower than that for the samples sealed by conventional nickel salt $\left(2.6171 \times 10^{-9} \mathrm{~A} \mathrm{~cm}^{-2}\right)$. This thus reveals that the samples sealed 

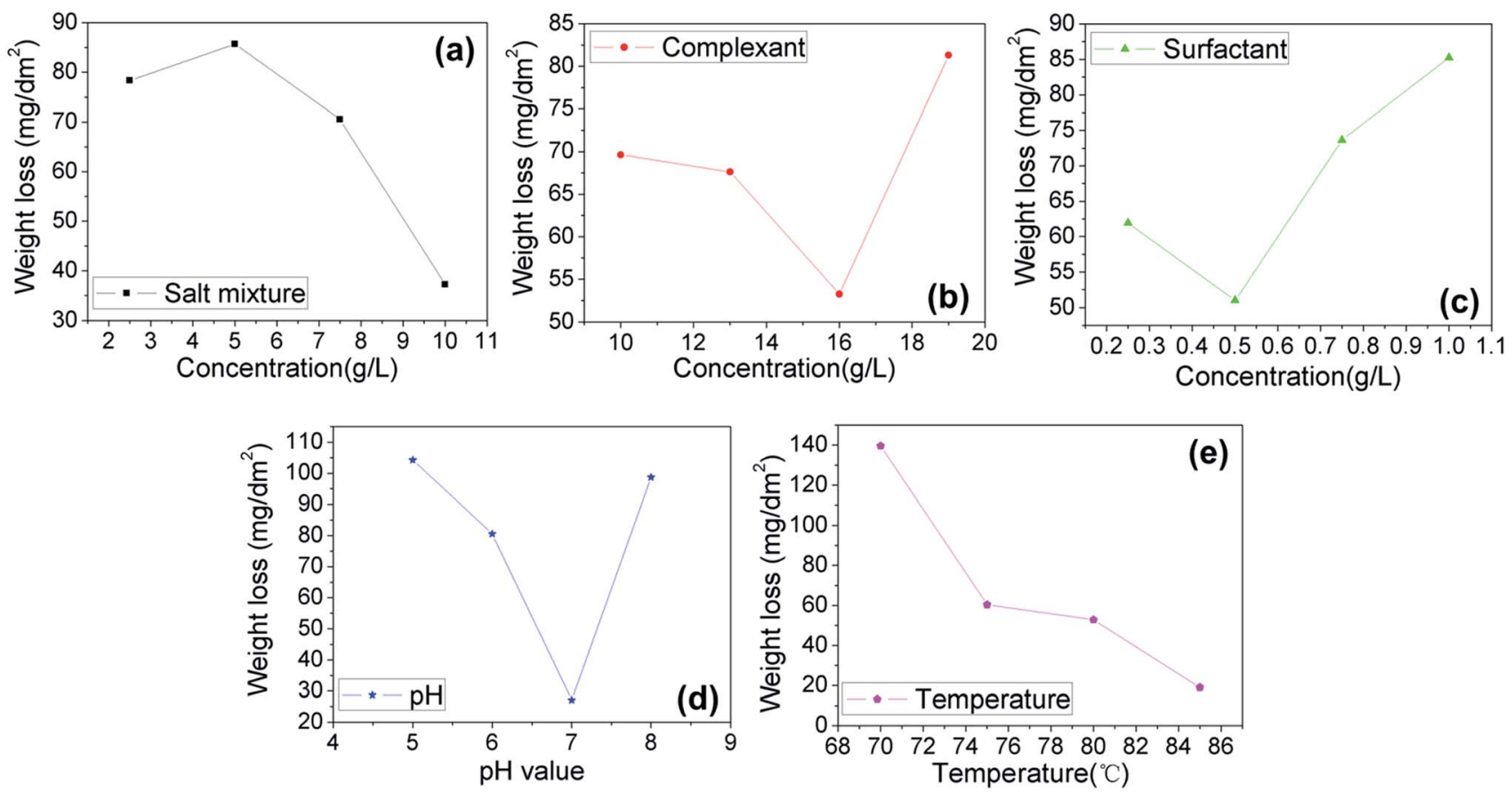

Fig. 3 The influence of different factors on the mean value of the weight loss.

by alkaline earth metal salt have a higher corrosion resistance as compared to those sealed by nickel salt under neutral $\mathrm{pH}$ conditions, although a comparable corrosion resistance can be noted for the both salts-sealed samples under acidic and alkaline $\mathrm{pH}$ conditions.

(b) AC impedance spectroscopy analysis. The EIS measurements were conducted on the samples sealed by the alkaline earth metal salt and nickel salt. The socking solution adopted for the measurement was a $3.5 \% \mathrm{NaCl}$ solution, with the socking time of 6 h, $3 \mathrm{~d}, 7 \mathrm{~d}, 13 \mathrm{~d}, 18 \mathrm{~d}, 24 \mathrm{~d}$ and $30 \mathrm{~d}$ (see Fig. 5a-d).

From Fig. 5(a and b), it is clear that the EIS spectra of the sealed samples are primarily composed of high-frequency and low-frequency capacitive loops. The part in the intermediate to high frequency range can reflect the main properties of the porous layer the AAO film, while the part at low frequencies can be a reflection of the main properties of the barrier layer. Based on the equivalent circuit shown in Fig. S2 of the ESI, $\uparrow$ the Nyquist plots presented in Fig. 5(a and b) are fitted, where $R_{1}$, $\mathrm{CPE}_{1}, R_{2}, \mathrm{CPE}_{2}$ and $\mathrm{CPE}_{3}$ are the electric resistance of the electrolyte, capacitance and resistance of the pore wall of the porous layer, resistance of the barrier layer, and capacitance of the pore wall of the porous layer, respectively. Note that the resistance of the barrier layer was not considered in the present EIS test, which is due to the extreme big value of the fitted resistance,

Table $1 \mathrm{~L} 16\left(4^{5}\right)$ orthogonal design for obtaining the optimal hole sealing conditions

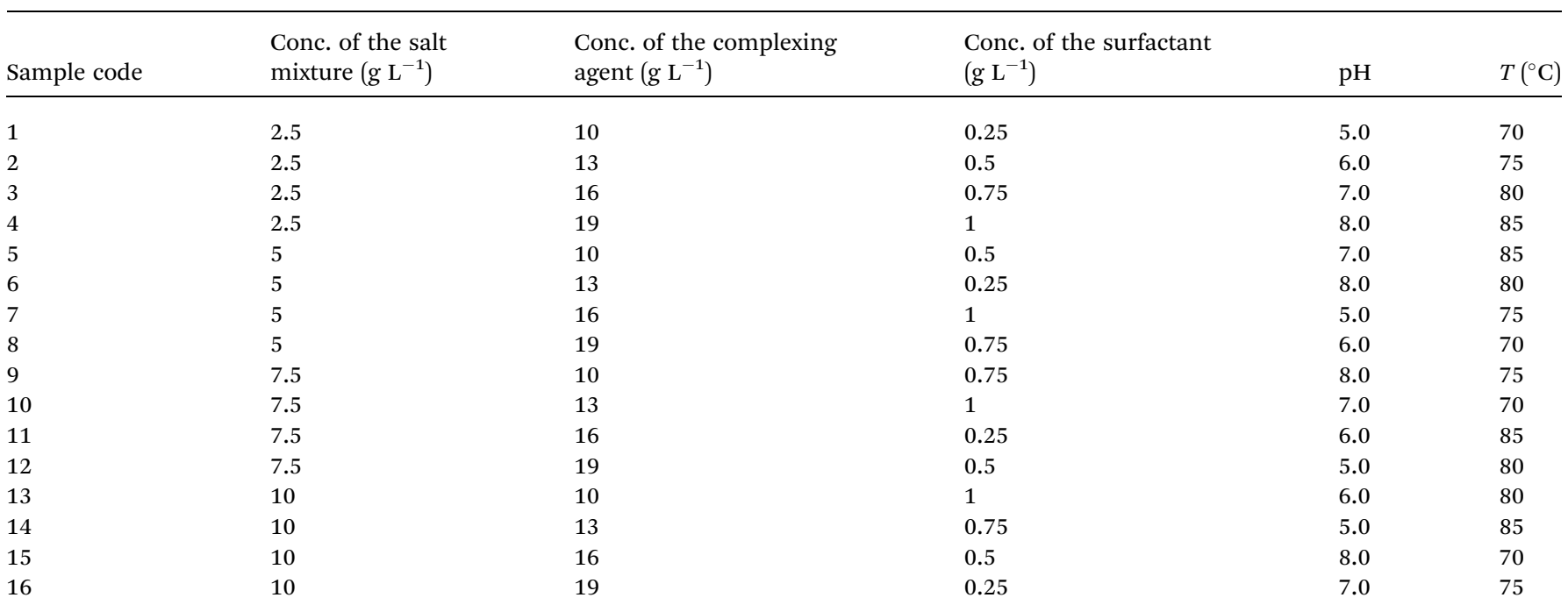


Table 2 The variance analysis of the weight loss index

\begin{tabular}{|c|c|c|c|c|c|}
\hline Factor & Square of deviance & Degree of freedom & $F$ ratio & $\begin{array}{l}F_{0.05} \text { critical } \\
\text { value }\end{array}$ & $\begin{array}{l}F_{0.10} \text { critical } \\
\text { value }\end{array}$ \\
\hline Mixed salt & 5497.085 & 3 & 0.176 & 9.280 & 5.390 \\
\hline Complexing agent & 1588.895 & 3 & 0.051 & 9.280 & 5.390 \\
\hline Surfactant & 2620.265 & 3 & 0.084 & 9.280 & 5.390 \\
\hline $\mathrm{pH}$ & 12859.470 & 3 & 0.412 & 9.280 & 5.390 \\
\hline Temperature & 31238.265 & 3 & 1.000 & 9.280 & 5.390 \\
\hline Error & 53803.98 & 15 & - & - & - \\
\hline
\end{tabular}

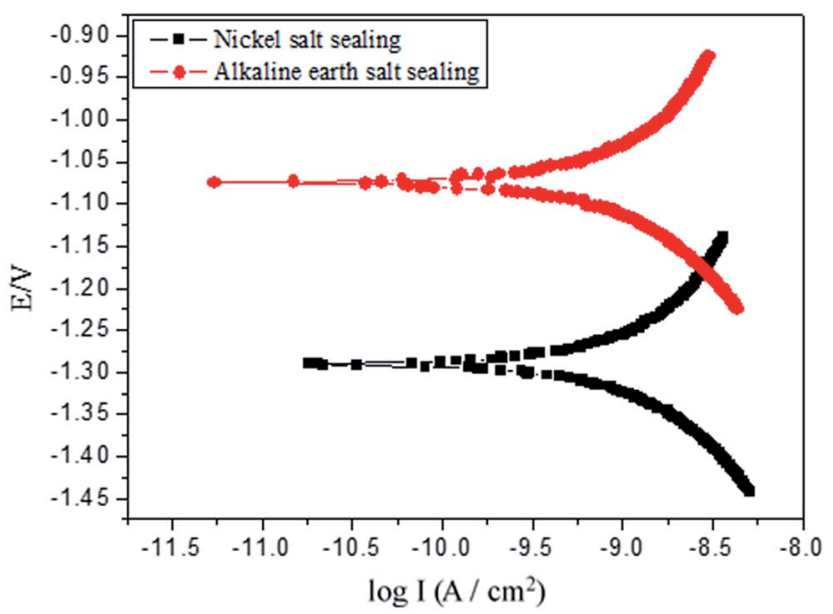

Fig. 4 The polarization curves measured in a $3.5 \% \mathrm{NaCl}$ solution.

which can reach as high as $10^{21}$ and hence suggests the insulating state of the barrier layer. As a result, the $\mathrm{CPE}_{2}$ and $\mathrm{CPE}_{3}$ play the main role in circuit connection. From Fig. $5 \mathrm{a}$, it can be noted that the capacitive loops at high frequencies are gradually expanded over time, while those at low frequencies are almost unchanged. Such a tendency can be more clearly noticed through the frequency- $|Z|$ patterns shown in Fig. 5c. These results reveal that the porous layer of the AAO film reacts with the $\mathrm{NaCl}$ solution, but there is no reaction at the barrier layer. On the other hand, the capacitive loops are expanded as well at high frequencies over time as for the samples sealed by alkaline earth metal salt, together with the almost unchanged capacitive loops at low frequencies. The frequency- $|Z|$ patterns given in Fig. 5d further clarify such a tendency. These results are a good indication of the reaction between the porous layer of the AAO film and the $\mathrm{NaCl}$ solution. Nevertheless, corrosion does not take place because the part at low frequencies is basically unchanged; the barrier layer does not contact with the $\mathrm{NaCl}$ solution. To conclude, within the socking time, the $\mathrm{NaCl}$ solution only interacts with the sealed porous layer, but does not etch off it, thus suggesting that it actually does not contact with the barrier layer.

Tables 4 and 5 present the electrochemical parameters related to the equivalent circuit. CPE-T and CPE-P represent capacitance and similarity level (a dimensionless constant) against $\mathrm{CPE}$. It can be found that $\mathrm{CPE}_{1}-\mathrm{T}$ and $\mathrm{CPE}_{3}-\mathrm{T}$ are varied to a small extent, while the values of the $\mathrm{CPE}_{1}-\mathrm{P}$ and $\mathrm{CPE}_{3}-\mathrm{P}$ increase constantly, indicating the growing divergence from the "pure capacitance". The resistance $R_{2}$ of the porous layer is a critical index to reflect the sealing quality of the porous layer. Generally, the higher the resistance of the inner pores of the porous layer, the lower the conductivity of the porous layer; this is corresponding to the better sealing effect. The resistance of the porous layer is lowered with socking time (Table 4). Importantly, in each time period, the measured resistance $R_{2}$ as for alkaline earth metal salt-sealed sample is higher than that for nickel salt-sealed one, indicating the superior corrosion resistance of the former; this is in good agreement with the potentiodynamic scanning result.

\section{Microscopic morphology analysis}

Fig. 6a-c shows the surface morphologies of the unsealed AAO sample, and the samples sealed by the nickel salt and alkaline earth metal salt, respectively. Fig. 6d presents the local crosssection morphology of the alkaline earth metal salt-sealed sample. For the unsealed sample (Fig. $6 \mathrm{a}$ and the selectively magnified image as the inset), the honeycomb-like porous structure can be observed. The rounded and complete pores, with the size of 10-20 nm, are uniformly distributed over the AAO film surface, without discernible broken or connected holes. A large quantity of micropores still exists on the surface of the sample as sealed by the nickel salt (Fig. 6b), with a portion of pores on the surface of AAO film, which is in the sealing state. This is particularly unambiguous from the inset of Fig. 6b. Such a hole sealing can be a result of interactions between the nickel salt and $\mathrm{Al}_{2} \mathrm{O}_{3}$ or of the deposition and accumulation of the

Table 3 The parameter fitting for potentiodynamic scanning experiment

\begin{tabular}{lllr}
\hline & \multicolumn{2}{l}{ Electrochemical parameters } \\
\cline { 2 - 4 } Hole sealing mode & $E_{\text {corr }}(\mathrm{V})$ & $I_{\text {corr }}\left(\mathrm{A} \mathrm{cm}^{-2}\right)$ & $B_{\mathrm{c}}(\mathrm{mV})$ \\
\hline Sealed by nickel salt & -1.2098 & $2.6171 \times 10^{-9}$ & 369.94 \\
Sealed by alkaline earth salt & -1.0720 & $1.9788 \times 10^{-9}$ & 567.33 \\
a & & 507.65
\end{tabular}



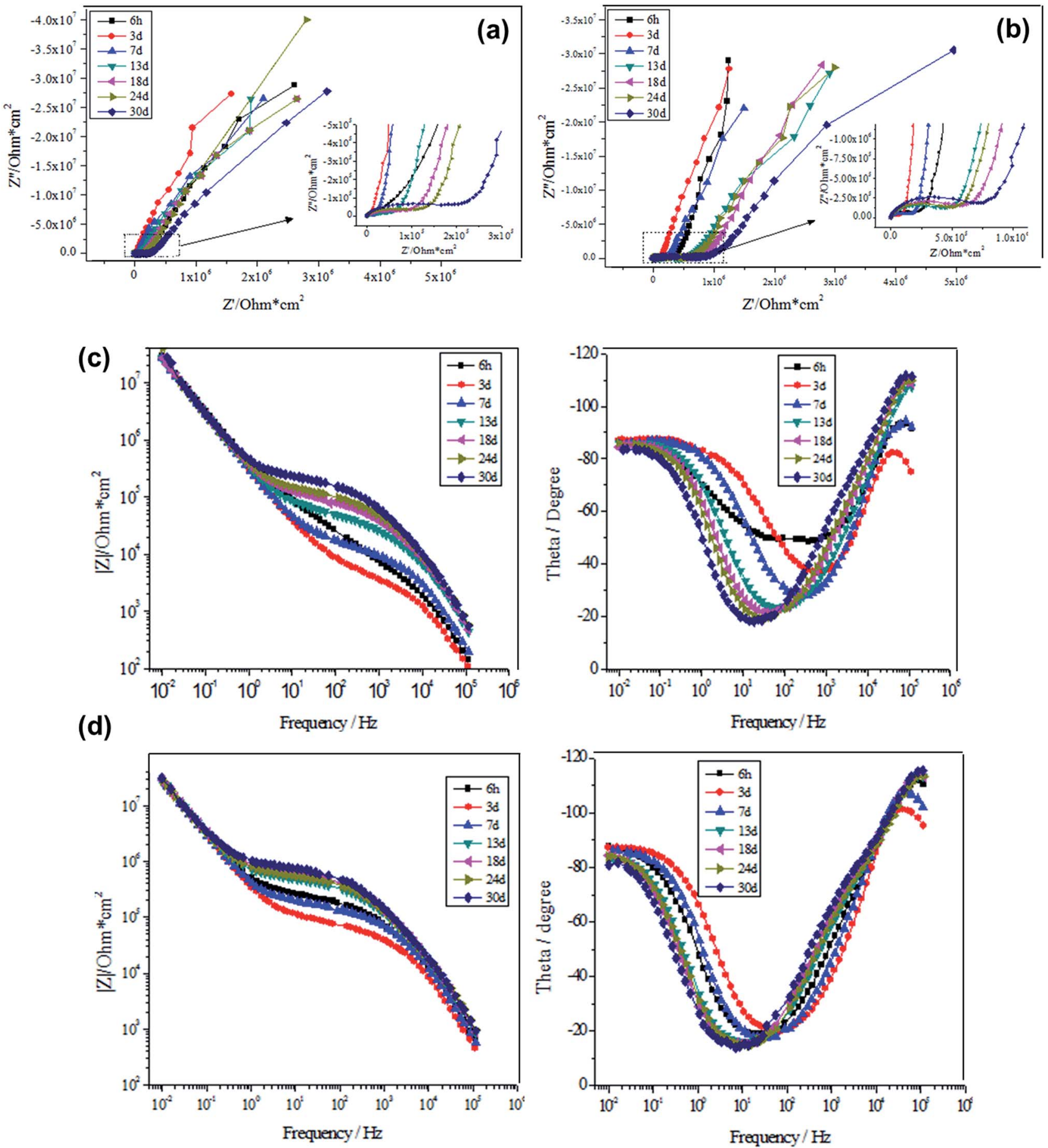

Fig. 5 (a-d) The AC impedance Nyquist of the AAO-based sample sealed by nickel salt (a) or alkaline earth metal salt (b) in a 3.5\% $\mathrm{NaCl}$ solution. The Bode plots of the AAO-based sample sealed by nickel salt (b) or alkaline earth metal salt (d) in a $3.5 \% \mathrm{NaCl}$ solution.

hydroxides into the micropores of the AAO film, leading to the filling of the local pore channels. Impressively, it can be noted in Fig. $6 \mathrm{c}$ that more micropores on the AAO film are in the sealing state as for the sample sealed by the alkaline metal salt as compared to that sealed by nickel salt shown in Fig. 6b. It is especially clear from the inset of Fig. 6c that much less honeycomb-like pores can be observed. This is most likely due to the generation of hydroxide deposits in the micropores of the AAO film. Upon interactions with complexant and surfactant, hydroxides are formed from $\mathrm{Ca}^{2+}$ and $\mathrm{Mg}^{2+}$ ions in the sealing solution of the alkaline earth metal salt. The red arrows shown in Fig. 6d indicate the nanoparticles with the size of approximately $10 \mathrm{~nm}$ for achieving the hole sealing. Some nanoparticles are deposited in the interior of the pore channels, with 
Table 4 The fitting values of the capacitance and resistance in porous layer which was immersed for different time

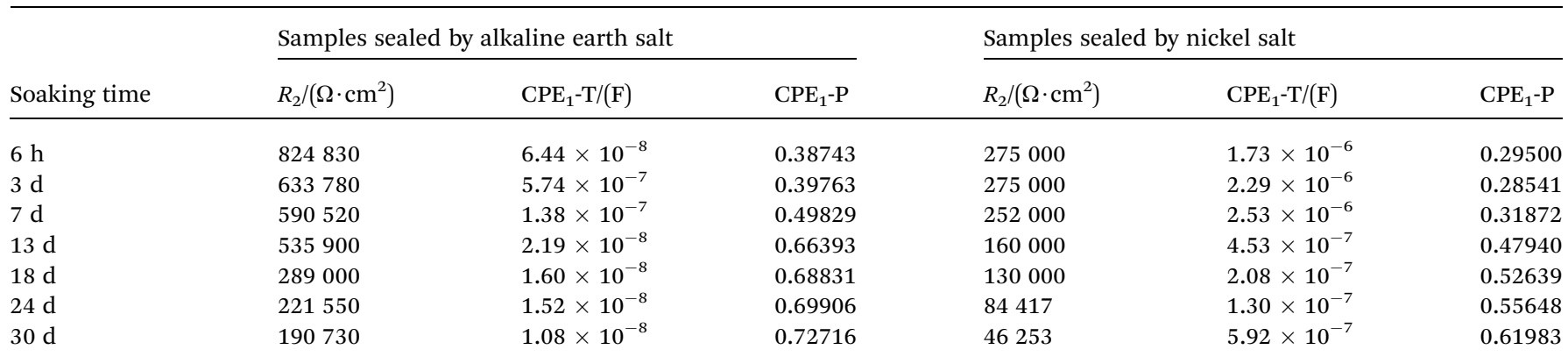

some other still not involved in the filling of the pore channels of the AAO film.

\section{Phase composition analysis}

The Al substrate composition can be confirmed by sharp characteristic XRD diffraction bands at approximately 38 and $65^{\circ}$ (Fig. S3 in the ESI $\dagger$ ). After anodic oxidation processing, a new weak and broad band emerges in the region between 20 and $30^{\circ}$, which can be well corresponding to the amorphous AAO film although the sharp Al-related band shelters the weak amorphous band of the $\mathrm{Al}_{2} \mathrm{O}_{3}$ film. ${ }^{9}$ We then further turn to FTIR and EDX spectra to confirm the elemental existence and chemical composition of the deposits in the pore channels of the AAO film, as presented in Fig. 7a and b, respectively. FTIR spectra clearly show the absorptions indexed to the AAO film, ${ }^{10}$ and to the sealing compositions, $\mathrm{Ca}(\mathrm{OH})_{2}$ and $\mathrm{Mg}(\mathrm{OH})_{2} \cdot{ }^{11} \mathrm{EDX}$ spectra of the sealed film further prove the existence of the elements of $\mathrm{Ca}$ and $\mathrm{Mg}$, in consistence with the FTIR spectra.

\section{Impact of various conditions on the potential-time $(E-t)$ curve for investigation of the hole sealing mechanism}

The variation tendency of the potential-time $(E-t)$ curves was employed to evaluate the hole sealing process rate. The gradual decrease of the potential on the $E-t$ curves can be an indication of an approximate steady sealing process. This study monitors and compares the speed for reaching a steady state through the $E-t$ curves under the condition of various sealing temperatures and $\mathrm{pH}$, as well as the solution compositions including surfactant, complexant and $\mathrm{pH}$ buffer. Consequently, the completion of the hole sealing process can be estimated. Meanwhile, the sealing speed can also be evaluated, facilitating a study of the kinetics of the sealing process. Within the measure time, some of the $E-t$ curves do not reach steady, but the speed for reaching steady can be determined on the basis of the potential variation rate.

(a) Impact of sealing temperatures on the $E-t$ curve. The sealing of the AAO film by using alkaline earth metal salts was conducted for $30 \mathrm{~min}$ at different temperatures, including 70 , 75,80 , and $85{ }^{\circ} \mathrm{C}$. The potential variation of the oxidation film over time is shown in Fig. 8 .

As shown in Fig. 8a, the potentials of the sealing processes at $70,75,80$ and $85{ }^{\circ} \mathrm{C}$ come to a steady state near 1300,1120 , 1000 , and $720 \mathrm{~s}$. The higher the sealing temperature, the shorter the time to reach a stable potential during the sealing process. This can be due to the temperature-induced enhancement of the transfer and diffusion of various ions including $\mathrm{Ca}^{2+}, \mathrm{Mg}^{2+}$, and $\mathrm{CH}_{3} \mathrm{COO}^{-}$, etc. This reveals that increasing the temperature can drive more ions and compound molecules into the pores of the AAO film. On the other hand, the water ionization is an endothermic process, which indicates that the higher temperature facilitates the ionization of $\mathrm{H}_{2} \mathrm{O}$ and hence generates more $\mathrm{H}^{+}$. The combination of a quantity of $\mathrm{H}^{+}$ions with the atom $\mathrm{N}$ of the $\mathrm{N}\left(\mathrm{CH}_{2} \mathrm{CH}_{2} \mathrm{OH}\right)_{3}$ molecules, which possesses the un-bonded electron pairs, leaving rich $\mathrm{OH}^{-}$ions in the interior of the pores. In addition, the hydrolysis of the $\mathrm{CH}_{3} \mathrm{COO}^{-}$is also endothermic, suggesting that the higher temperatures facilitate the $\mathrm{CH}_{3} \mathrm{COO}^{-}$hydrolysis and hence increase the concentration of $\mathrm{OH}^{-}$ions. Therefore, the higher the temperature, the higher the concentration of $\mathrm{OH}^{-}$ions, along with the higher

Table 5 The fitting values of the capacitance of the hole wall of the porous layer and capacitance of the barrier layer, which were immersed for different time





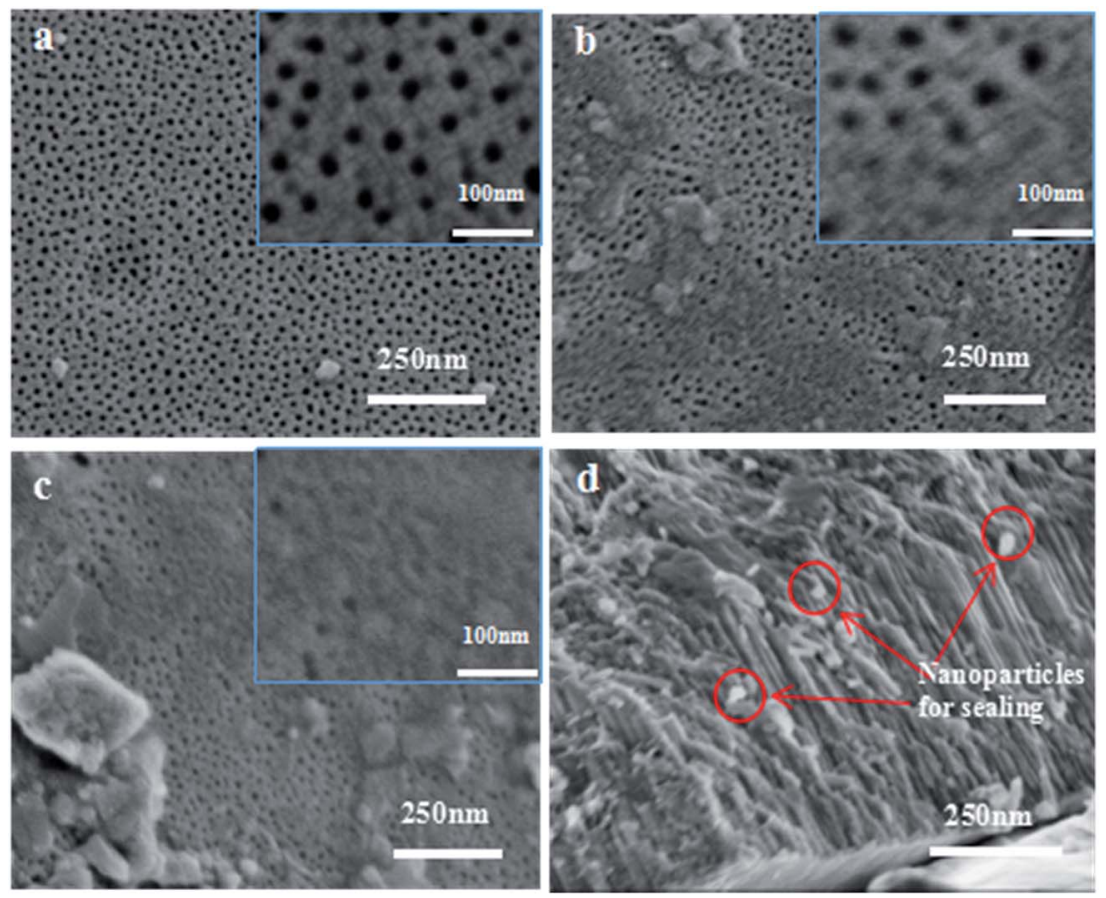

Fig. 6 SEM images of the samples before and after hole sealing ((a) unsealed sample; (b) sealed by nickel salt; (c, d) sealed by alkaline earth metal salt).

probability of the combination with $\mathrm{Ca}^{2+}$ and $\mathrm{Mg}^{2+}$ ions to form deposits. The higher rate of sealing the AAO film can hence be obtained. It can also be found that the potential for the hole sealing comes to a stabilization state in the first place at higher temperatures (Fig. 8a).

(b) Impact of the surfactant on the $\boldsymbol{E}-\boldsymbol{t}$ curve. Two sheets of the AAO samples were placed in the sealing solution of the alkaline earth metal salts for performing the hole sealing at $85{ }^{\circ} \mathrm{C}$ for $30 \mathrm{~min}$. The potential variation of the AAO film over time is presented in Fig. $8 \mathrm{~b}$.

The potential of the sample sealed in the presence of the surfactant fluctuates greatly over the time period of 0-600 s, followed by a stabilization state at $1800 \mathrm{~s}$ (but still with a rising tendency). In contrast, the potential of the sample sealed in the presence of the surfactant becomes stable around $720 \mathrm{~s}$. This indicates that the addition of the surfactant can enable the sealing process to be more quickly stabilized, facilitating the sealing of the AAO film. The surfactant $\mathrm{C}_{24} \mathrm{H}_{32} \mathrm{O}_{7} \mathrm{~S}_{2} \mathrm{Na}_{2}$ possesses the excellent resistance to hard water and can form chelate compounds with $\mathrm{Ca}^{2+}$ and $\mathrm{Mg}^{2+}$, reducing the probability of forming the deposits as a result of the reaction between $\mathrm{Ca}^{2+}$ and $\mathrm{Mg}^{2+}$ metal ions and $\mathrm{OH}^{-}$ions in the solution. This can thereby soften the water. On the other hand, there are two negative charges on the $\mathrm{C}_{24} \mathrm{H}_{32} \mathrm{O}_{7} \mathrm{~S}_{2} \mathrm{Na}_{2}$ molecules, which improve its solubility in the electrolyte solutions. Such a strong dispersion power of $\mathrm{C}_{24} \mathrm{H}_{32} \mathrm{O}_{7} \mathrm{~S}_{2} \mathrm{Na}_{2}$ molecules can render $\mathrm{Ca}^{2+}$ and $\mathrm{Mg}^{2+}$ ions dispersive, reducing their aggregations on the surface of the AAO film and hence avoiding the generation of the deposits on the AAO surface resulting from the $\mathrm{Ca}^{2+}$ and $\mathrm{Mg}^{2+}$ ions. The AAO surface can thus be refrained from dusting.
By contrast, the $\mathrm{OH}^{-}$ions, as accumulated in the solution without the surfactant, progressively react with $\mathrm{Ca}^{2+}$ and $\mathrm{Mg}^{2+}$ ions. The deposits can be formed both in the bulk solution and on the surface of the AAO film in the fashion of accumulation. It can also be noted in Fig. 8b that it is rather difficult for stabilizing the potential.

For the sealing solution with the surfactant $\mathrm{C}_{24} \mathrm{H}_{32} \mathrm{O}_{7} \mathrm{~S}_{2} \mathrm{Na}_{2}$, a stable $E-t$ curve can be obtained in a faster way, along with an effective sealing of the AAO film. The vast majority of such surfactant molecules, with the molecular weight of 542, dissociates in the bulk solution and on the external surface of the AAO film. Only a trace amount of the surfactant molecules can enter the 10-20 nm-sized micropores of the AAO film. Assuming the spherical model of the surfactant $\mathrm{C}_{24} \mathrm{H}_{32} \mathrm{O}_{7} \mathrm{~S}_{2} \mathrm{Na}_{2}$ molecules, the diameter of the spheres can be calculated according to eqn (1):

$$
D=\sqrt[3]{\frac{6 M}{\rho N_{\mathrm{A}} \pi}}
$$

where $D, M, \rho$, and $N_{\mathrm{A}}$ are diameter, molecular molar mass, density, and Avogadro constant $\left(6.02 \times 10^{23}\right)$, respectively. Note that this equation is applied to the subject in the liquid and solid states, but not in the gaseous state.

Based on the calculation, the diameter of the spherical model of the $\mathrm{C}_{24} \mathrm{H}_{32} \mathrm{O}_{7} \mathrm{~S}_{2} \mathrm{Na}_{2}$ molecules can reach approximately $11.40 \AA$. In the bulk solution, the molecular diameters of $\mathrm{H}_{2} \mathrm{O}$, $\mathrm{N}\left(\mathrm{CH}_{2} \mathrm{CH}_{2} \mathrm{OH}\right)_{3}, \mathrm{CH}_{3} \mathrm{COO}^{-}, \mathrm{OH}^{-}$, and $\mathrm{NH}_{4}{ }^{+}, \mathrm{Ca}^{2+}$, and $\mathrm{Mg}^{2+}$ are estimated as $3.85,7.49,5.66,2.37,1.43,1.00$ and $0.89 \AA$, respectively. Actually, a long-chain model can be assigned to the $\mathrm{C}_{24} \mathrm{H}_{32} \mathrm{O}_{7} \mathrm{~S}_{2} \mathrm{Na}_{2}$ molecules, and their molecular diameter is thus 

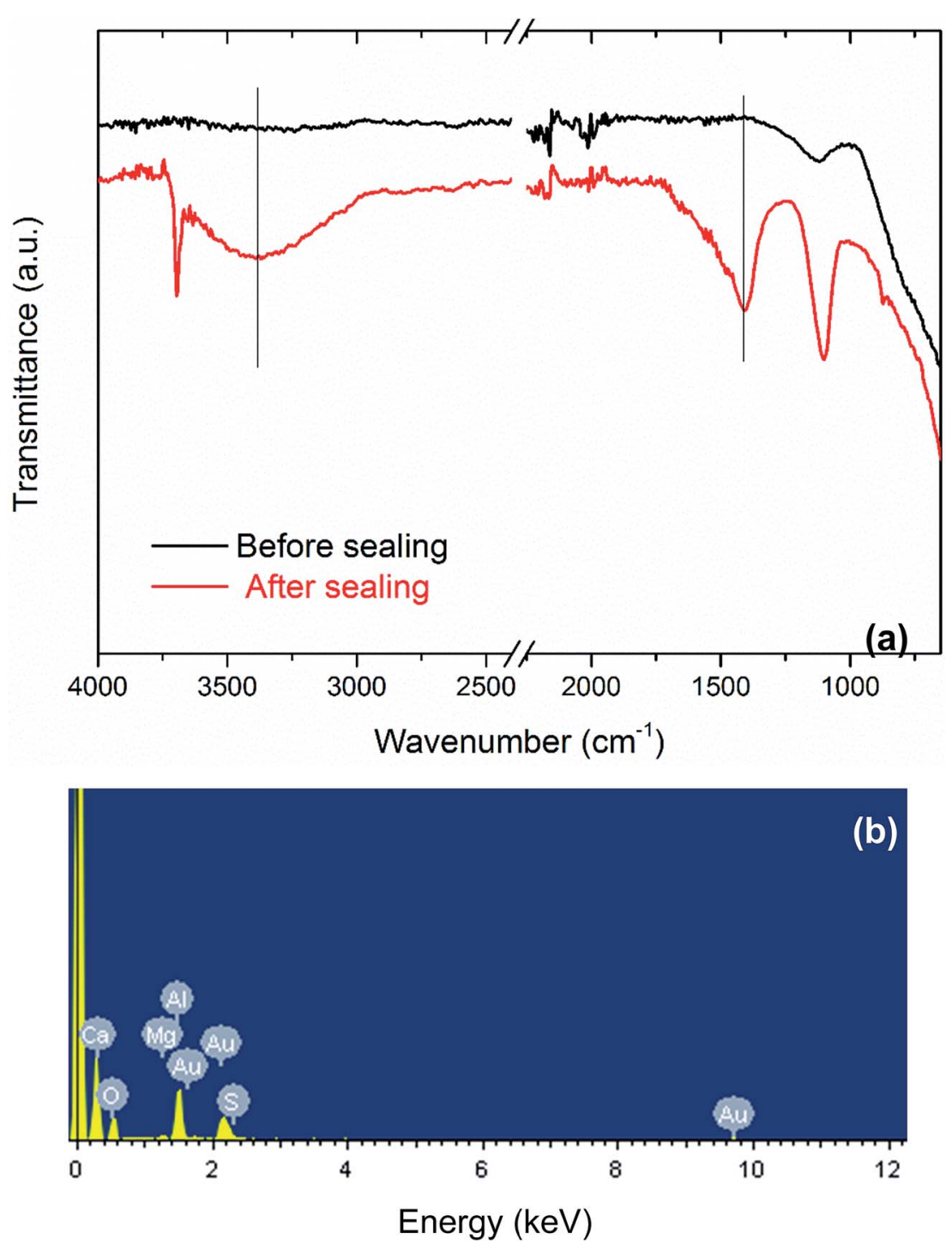

Fig. 7 (a) FTIR spectra of the AAO samples before and after sealing by alkaline earth metal salt. (b) EDX spectrum of the sample sealed by alkaline earth metal salt.

greater than $11.40 \AA$, especially considering their hydration state in the aqueous solution. Consequently, the highest number of the $\mathrm{C}_{24} \mathrm{H}_{32} \mathrm{O}_{7} \mathrm{~S}_{2} \mathrm{Na}_{2}$ molecules, capable of simultaneously entering the micropores of the AAO film, can be estimated to be as high as $6-13$, provided that the velocity of migration of the molecules into the AAO film is the same as that of the ions in the solution. The completely homogenous dispersion of $\mathrm{C}_{24} \mathrm{H}_{32} \mathrm{O}_{7} \mathrm{~S}_{2} \mathrm{Na}_{2}$ molecules $\left(0.5 \mathrm{~g} \mathrm{~L}^{-1}\right)$ indicates that migration of each $10 \mathrm{~nm}$ into the $20 \mathrm{~nm}$-sized pores of the AAO film corresponds to the number of the $\mathrm{C}_{24} \mathrm{H}_{32} \mathrm{O}_{7} \mathrm{~S}_{2} \mathrm{Na}_{2}$ molecules of 3.4 or less (most of them forms chelate compounds with $\mathrm{Ca}^{2+}$ and $\mathrm{Mg}^{2+}$ ). When the AAO film is just immersed into the solution, the molecules in the bulk solution diffuses into the micropores of the AAO film. Due to a higher molecular weight of $\mathrm{C}_{24} \mathrm{H}_{32} \mathrm{O}_{7} \mathrm{~S}_{2} \mathrm{Na}_{2}$, the diffusion is slow, revealing that the other smaller molecules can initially diffuse into the pores. The concentration of the $\mathrm{C}_{24} \mathrm{H}_{32} \mathrm{O}_{7} \mathrm{~S}_{2} \mathrm{Na}_{2}$ molecules strikes a balance between inside and outside of the pores of the AAO film, resulting in the cease of the diffusion. After chelated with $\mathrm{C}_{24} \mathrm{H}_{32} \mathrm{O}_{7} \mathrm{~S}_{2} \mathrm{Na}_{2}$ molecules in a trace amount, the $\mathrm{Ca}^{2+}$ and $\mathrm{Mg}^{2+}$ cannot affect their combination with $\mathrm{OH}^{-}$ions. The process of diffusing the surfactant molecules and various ions and molecules is illustrated by steps (I), (II) and (III) (see Scheme 1), where the $\mathrm{C}_{24} \mathrm{H}_{32} \mathrm{O}_{7} \mathrm{~S}_{2} \mathrm{Na}_{2}$ molecules are corresponding to the blue spheres, and the remaining molecules and ions are also indicated by using other colored spheres. The diffusion starts in the step (I); small molecules and ions arrives at the pores of the AAO film in the step (II); the solute concentration reaches a balanced state between inside and outside of the pores of the AAO film, and then the diffusion stops in the step (III).

(c) Impact of the complexant on the $\boldsymbol{E}-\boldsymbol{t}$ curve. To achieve the sealing treatment, two sheets of the same AAO samples were placed into the sealing solutions of alkaline earth metal salt in the presence and absence of the complexant. The sealing reaction was performed at $85{ }^{\circ} \mathrm{C}$ for $30 \mathrm{~min}$. The potential variation 



Fig. 8 Investigation of various sealing conditions on $E-t$ curves, including sealing temperature (a), surfactant (b), complexant (c), buffer solution (d) and $\mathrm{pH}(\mathrm{e})$ conditions.

of the coating surface over time is shown in Fig. 8c. The potential of the electrode surface for the sealing sample without involving complexant is increased in a fast way in the range of 0-400 s, while the rise become slow in the range of 400-1800 s, which most likely reveals that the velocity of the deposit formation is changed. It can be informed from the physicochemical properties of $\mathrm{N}\left(\mathrm{CH}_{2} \mathrm{CH}_{2} \mathrm{OH}\right)_{3}$ that the unpaired electrons can strongly complex with the $\mathrm{H}^{+}$, leading to the rise of the $\mathrm{pH}$ around the pores of the AAO film. On the other hand, there is a lower concentration of $\mathrm{OH}^{-}$ions in the sealing solution in the presence of the $\mathrm{N}\left(\mathrm{CH}_{2} \mathrm{CH}_{2} \mathrm{OH}\right)_{3}$. When the speed of the deposit formation from the reaction between $\mathrm{OH}^{-}$ions and
$\mathrm{Ca}^{2+}$ and $\mathrm{Mg}^{2+}$ ions is higher than that of the $\mathrm{OH}^{-}$generation, the potential increase becomes slow. For the sealing system with the compelxent $\mathrm{N}\left(\mathrm{CH}_{2} \mathrm{CH}_{2} \mathrm{OH}\right)_{3}$, the $\mathrm{OH}^{-}$concentration is limited for the generation of the deposit in the pores of the AAO film, leading to a low sealing speed. The potential is thus difficult to be stabilized. In addition, it is found that the composition of the sulfuric acid-based AAO film mainly consists of the $78.9 \% \mathrm{Al}_{2} \mathrm{O}_{3}, 20.2 \% \mathrm{Al}_{2}\left(\mathrm{SO}_{4}\right)_{3}$, and $0.9 \% \mathrm{H}_{2} \mathrm{O}$. As a result, with prolonging the sealing time, a little amount of $\mathrm{Al}^{3+}$ is released from the AAO film, adversely affecting the generation of the $\mathrm{Ca}^{2+}$ and $\mathrm{Mg}^{2+}$ ions-related deposits in the pores of the AAO film. However, the complexing constant for the reaction 

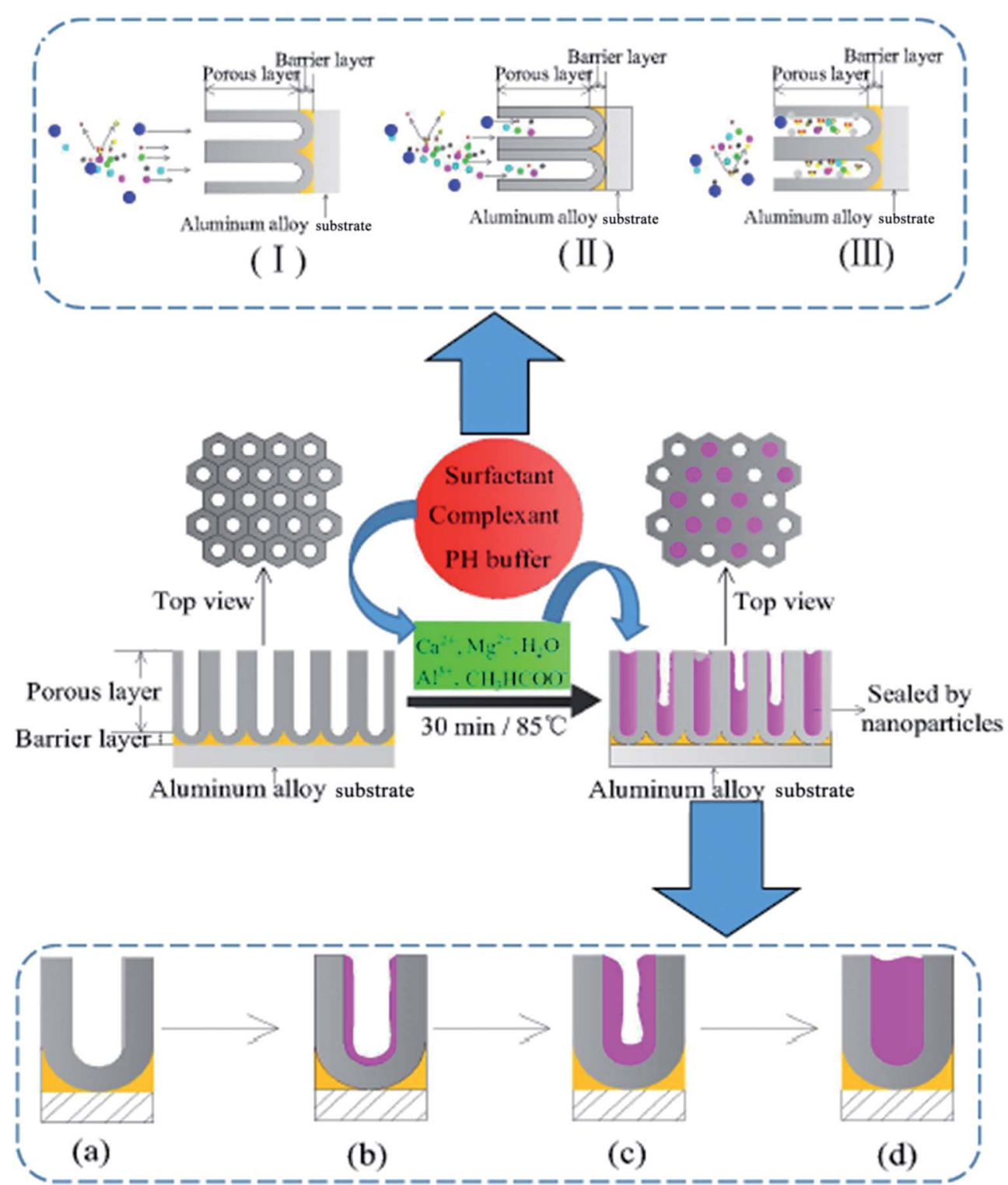

Scheme 1 Schematic illustration of the hole sealing process based on the alkaline earth metal salt.

between the complexant $\mathrm{N}\left(\mathrm{CH}_{2} \mathrm{CH}_{2} \mathrm{OH}\right)_{3}$ and $\mathrm{Al}^{3+}$ ions is larger than that for the reaction between $\mathrm{N}\left(\mathrm{CH}_{2} \mathrm{CH}_{2} \mathrm{OH}\right)_{3}$ and $\mathrm{Ca}^{2+}$ and $\mathrm{Mg}^{2+}$ ions, i.e., the complexant plays a role in specific screening of the $\mathrm{Al}^{3+}$ ions. The electrode potential of the sealed sample in the presence of the complexant can be stabilized quickly around $720 \mathrm{~s}$ (Fig. 8c).

(d) Impact of the buffer on the $\boldsymbol{E}-\boldsymbol{t}$ curve. To seal the AAO samples, two sheet samples were placed in the alkaline earth metal solutions with and without the buffers at $85{ }^{\circ} \mathrm{C}$ for $30 \mathrm{~min}$. The potential variation of the coating surface over time is depicted in Fig. 8d. For the sealing system without the buffer solution, the electrode potential of the sealed samples surface can be balanced around $1180 \mathrm{~s}$, while the balance is obtained near $720 \mathrm{~s}$ as for the system with the buffer. This is an indication that the addition of the buffer helps to seal the sample effectively. Besides, the addition of the buffer reagent facilitates the stabilization of the $E-t$ curve in the potential balance region, with a little fluctuation. During this process, the buffer mitigates the $\mathrm{pH}$ ascending velocity, but ensures the content of $\mathrm{OH}^{-}$ ions to be sufficient for the deposit formation from $\mathrm{Ca}^{2+}$ and $\mathrm{Mg}^{2+}$, avoiding the undesirable result that the deposits precipitate too fast to make a fluffy filling and to lead to a bad sealing.

(e) Impact of the solution pH on the $\boldsymbol{E}-\boldsymbol{t}$ curve. The sealing of the AAO samples was performed at $\mathrm{pH} 5,6,7,8$ and 9 at $85{ }^{\circ} \mathrm{C}$ for $30 \mathrm{~min}$, with the potential variation of the coating surface over time as shown in Fig. 8e. In the $\mathrm{pH}$ range of 5-7, increasing the $\mathrm{pH}$ value facilitates the stabilization of the $E-t$ curve. At $\mathrm{pH}$ 8 , the high rising speed of the $E-t$ curve can be noted, but the $E-$ $t$ curve cannot reach a steady state; an initial rising and then gradually lowering can be seen. The deposit precipitates out quickly at such a $\mathrm{pH}$, with the fluffy product generated. At $\mathrm{pH} 9$, a constant rising tendency of the $E-t$ curve can be noted, and a steady state cannot be realized. It is thus informed that the hole sealing can effectively proceed in the appropriate $\mathrm{pH}$ 


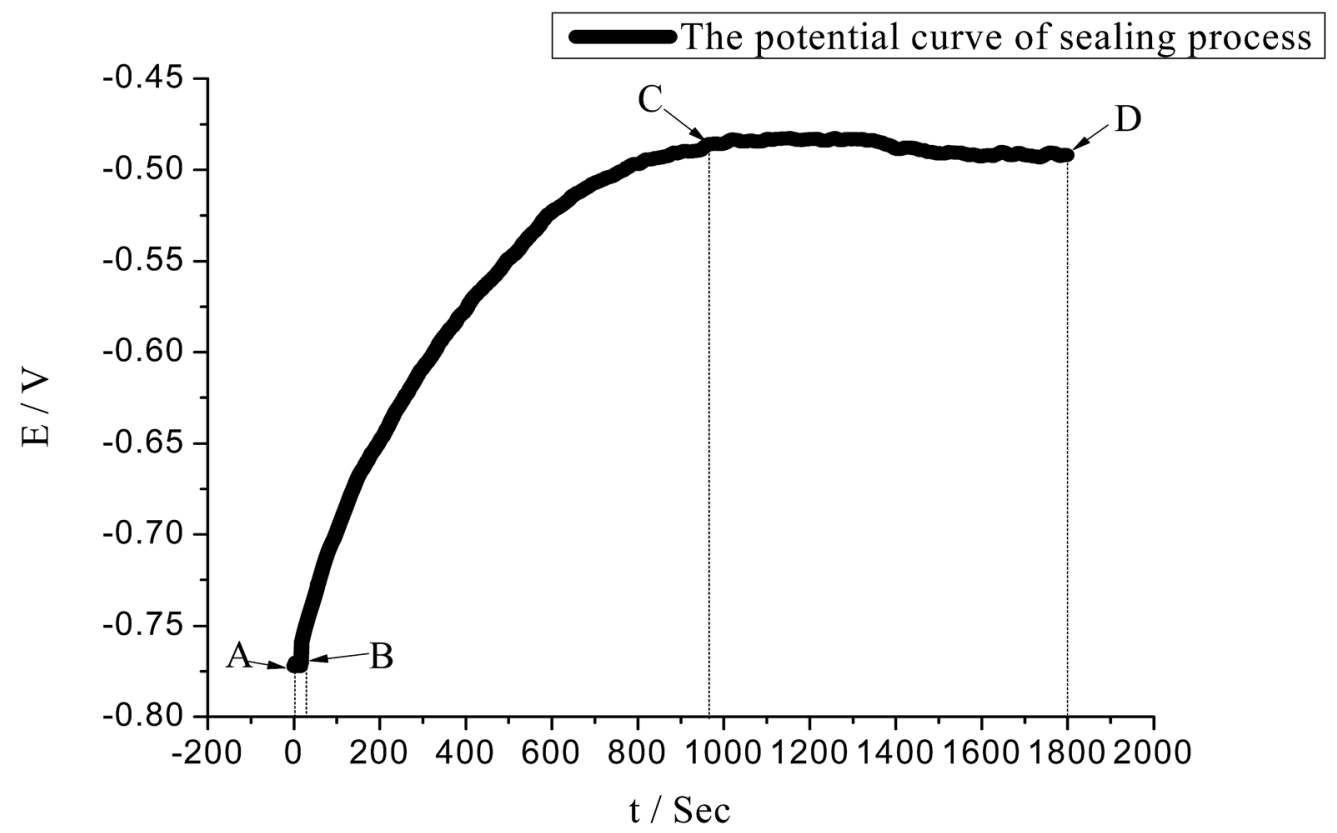

Fig. 9 The $E-t$ curve obtained during sealing by alkaline earth metal salt.

range. When the $\mathrm{pH}$ value is excessively high, the free $\mathrm{Ca}^{2+}$ and $\mathrm{Mg}^{2+}$ ions in the solution would form deposits before their migration into the pores of the AAO film, being unfavorable to the hole sealing and hence lowering the sealing quality. Over the $\mathrm{pH}$ range involved in this study, the optimal $\mathrm{pH}$ value of the sealing solution is estimated as 7 , which is most favorable for sealing the micropores of the AAO film.

\section{Discussion of the mechanism underlying the alkaline earth metal salt-based hole sealing}

For hole sealing with the alkaline earth metal salt, the potential variation of the surface of the AAO film (with a $12 \mu \mathrm{m}$ thickness) and sealing mechanism were explored, with the resultant $E-t$ curve and schematic illustration of the sealing process presented in Fig. 9 and Scheme 1, respectively.

It can be noted that the A-B region of the $E-t$ curve is indexed to the migration of the ions into the AAO film in the bulk solution. Over such a region, no deposits appear in the pores of the AAO film. The status of the pores of the AAO film is displayed in Scheme 1a. Owing to the conditions without involving external stirring, there exists no forced convection, revealing that such a process is controlled by the diffusion-related mass transfer. The concentration difference (or concentration gradient) between the inside and outside of the AAO film can be regarded as the impetus for the mass transfer. According to the diffusion kinetics, the existence of the convection at a certain strength is a requirement for realizing the stable diffusion. Consequently, the ion diffusion in such a process can be regarded as the unstable diffusion process. Assuming that the ion concentration is designated as $c$, the relationship between the distance (from outside to inside of the pores of the AAO film) and diffuse time satisfy the Fick's second law as described by using eqn (2).

$$
\frac{\partial c}{\partial t}=D \frac{\partial^{2} c}{\partial x^{2}}
$$

where $x$ and $c$ represent the parameters relating to the thickness of the AAO film, and concentrations of the cations and anions, respectively. $D$ is the ionic diffusion coefficient.

Over the B-C region, the $E-t$ curve rises constantly, corresponding to the period of accumulating the nano-deposits in the micropores of the AAO film. In the presence of a trace amount of $\mathrm{C}_{24} \mathrm{H}_{32} \mathrm{O}_{7} \mathrm{~S}_{2} \mathrm{Na}_{2}$, it is insufficient for chelating the $\mathrm{Ca}^{2+}$ and $\mathrm{Mg}^{2+}$ at a high concentration, facilitating the interactions between these alkaline metal ions and $\mathrm{OH}^{-}$at a certain concentration and hence forming deposit particles that can fill the film pores. The reactions involved in the sealing process are proposed as eqn (3)-(12).



$$
\begin{gathered}
\left(\mathrm{CH}_{2} \mathrm{CH}_{2} \mathrm{OH}\right)_{3} \mathrm{~N}+\mathrm{H}_{2} \mathrm{O}=\mathrm{H}\left(\mathrm{CH}_{2} \mathrm{CH}_{2} \mathrm{OH}\right)_{3} \mathrm{~N}^{+}+\mathrm{OH}^{-} \\
3\left(\mathrm{CH}_{2} \mathrm{CH}_{2} \mathrm{OH}\right)_{3} \mathrm{~N}+\mathrm{Al}^{3+}=\mathrm{Al}\left(\mathrm{CH}_{2} \mathrm{CH}_{2} \mathrm{O}\right)_{3} \mathrm{~N}+3 \mathrm{H}^{+} \\
6 \mathrm{CH}_{3} \mathrm{COO}^{-}+\mathrm{Al}^{3+}=\mathrm{Al}\left(\mathrm{CH}_{3} \mathrm{COO}\right)_{6}{ }^{3-}
\end{gathered}
$$$$
2 \mathrm{Al}(\mathrm{OH})_{3}+\mathrm{Al}\left(\mathrm{CH}_{3} \mathrm{COO}\right)_{6}{ }^{3-}=\mathrm{Al}_{3}(\mathrm{OH})_{3}\left(\mathrm{CH}_{3} \mathrm{COO}\right)_{6}+3 \mathrm{OH}^{-}(9)
$$$$
\mathrm{NH}_{4}{ }^{+}+\mathrm{OH}^{-}=\mathrm{NH}_{3} \cdot \mathrm{H}_{2} \mathrm{O}
$$$$
\mathrm{Ca}^{2+}+2 \mathrm{OH}^{-}=\mathrm{Ca}(\mathrm{OH})_{2} \downarrow
$$$$
\mathrm{Mg}^{2+}+2 \mathrm{OH}^{-}=\mathrm{Mg}(\mathrm{OH})_{2} \downarrow
$$

In such a process, the chelating reactions as illustrated in eqn (3) and (4) mainly occurs in the bulk solution, which is the reasons for observing the phenomenon that the turbid solution cannot be seen when a certain concentration of $\mathrm{OH}^{-}$ions exists in the bulk solution. The eqn (5) and (6) can basically elucidate the increase of the $\mathrm{OH}^{-}$concentration. When the concentration of the $\mathrm{OH}^{-}$ions in the pores of the AAO film arrives at a certain point, the deposits can be formed from the reactions between the $\mathrm{OH}^{-}$ions and $\mathrm{Ca}^{2+}$ and $\mathrm{Mg}^{2+}$ ions. The deposits accumulate on the inner wall of the pores of AAO film. The eqn (7) reflects the shielding effect of triethanolamine on the $\mathrm{Al}^{3+}$ ions, weakening their impact on the $\mathrm{Ca}^{2+}$ and $\mathrm{Mg}^{2+}$-based deposits. The interactions between $\mathrm{Al}^{3+}$ and $\mathrm{CH}_{3} \mathrm{COO}^{-}$can be displayed by eqn (8) and (9). The $\mathrm{NH}^{4+}$ ions given in eqn (8) stems from the $\mathrm{pH}$ buffer and has a buffering function to the rise of the concentration of $\mathrm{OH}^{-}$ions in the both the bulk solution and pores of the AAO films. This can thus mitigate the $\mathrm{pH}$ ascending velocity, but cannot inhibit the $\mathrm{pH}$ increase, helping to improve the quality of the deposits precipitated in the pores of the AAO film. The growth of the deposits in the pores of the AAO films is illustrated in Scheme $1(\mathrm{a}-\mathrm{d})$, where the purple portion of the cross-section corresponds to the deposits. With consuming the $\mathrm{Ca}^{2+}$ and $\mathrm{Mg}^{2+}$ ions in the pores of the AAO film, a concentration difference is gradually generated between the solution concentration and bulk solution of the pores of the AAO film, facilitating the continuous diffusion of the bulk solution into the film pores. The precipitation takes place along with the diffusion, until the concentration of the $\mathrm{C}_{24} \mathrm{H}_{32} \mathrm{O}_{7} \mathrm{~S}_{2} \mathrm{Na}_{2}$ molecules reach a point that can adequately chelate $\mathrm{Ca}^{2+}$ and $\mathrm{Mg}^{2+}$ ions in the film pores. At such a point, the formation of the deposits stop; in the meanwhile, the reaction also ceases. The ceasing point on the $E-t$ curve is corresponding to the point $\mathrm{C}$, together with the potential in a steady state. The C-D region of the $E-t$ curve keeps stable, with a complete sealing sate and a basically constant electrical resistance of the AAO layer. The distribution of the deposits in the film pores in the C-D region can be partly in the state as illustrated in Scheme 1(d), while the other part being in the state as depicted in Scheme 1(c). This can be well evidenced by the SEM observation as shown in Fig. $6 c$. In the state illustrated in Scheme 1(d), the film pores are completely filled by the deposits, indicating that the film pores can be fully filled before the $\mathrm{C}_{24} \mathrm{H}_{32} \mathrm{O}_{7} \mathrm{~S}_{2} \mathrm{Na}_{2}$ reaches a certain concentration in the film pores. For the state indexed to the film pores being not fully filled (Scheme 1(c)), the concentration of the
$\mathrm{C}_{24} \mathrm{H}_{32} \mathrm{O}_{7} \mathrm{~S}_{2} \mathrm{Na}_{2}$ reaches a point to sufficiently chelate $\mathrm{Ca}^{2+}$ and $\mathrm{Mg}^{2+}$ ions but not to generate the deposits. In the steady potential state, the ions in the bulk solution continues to diffuse into the film pores in an incomplete sealing state, until the solute concentration reaches a balanced status between the inside and outside of the pores (with the concentration gradient reduced to 0 ).

\section{Experimental}

\section{Materials and anodic oxidation processing}

The starting aluminum alloy adopted was a 6063-type plate (100 $\times 50 \times 2 \mathrm{~mm}^{3}$ ). The commonly-used sulfuric acid-based anodic oxidation system was used to anodically oxidize the aluminum alloy substrate based on the following anodic oxidation conditions:

Oxidation temperature: $20-25{ }^{\circ} \mathrm{C}$;

Current density: $1.2 \mathrm{~A} \mathrm{dm}^{-2}$;

And oxidation time: 30 min.

The thickness of the oxidation layer was controlled to be 12$15 \mu \mathrm{m}$. The nickel-free sealing processing was subsequently explored on the AAO film. The main steps for realizing this anodic oxidation and hole sealing are schematically illustrated in Fig. S1 of the ESI. $\dagger$ The compositions of the alkaline liquid used for washing the starting aluminum alloy plate were $\mathrm{NaOH}$ $\left(5 \mathrm{~g} \mathrm{~L}^{-1}\right), \mathrm{NaSiO}_{3}\left(10-20 \mathrm{~g} \mathrm{~L}^{-1}\right), \mathrm{Na}_{3} \mathrm{PO}_{4}\left(10 \mathrm{~g} \mathrm{~L}^{-1}\right), \mathrm{Na}_{2} \mathrm{CO}_{3}(10-$ $\left.20 \mathrm{~g} \mathrm{~L}^{-1}\right)$, and OP-10 $\left(1 \mathrm{~g} \mathrm{~L}^{-1}\right)$, while acidic washing liquid was comprised of $\mathrm{H}_{2} \mathrm{SO}_{4}(10 \%)$ and $\mathrm{HNO}_{3}(4 \%)$. The electrolyte used for electrochemical oxidation was a $\mathrm{H}_{2} \mathrm{SO}_{4}$ solution $\left(186 \mathrm{~g} \mathrm{~L}^{-1}\right)$. The rinsing was based on deionized (DI) water. The hole sealing treatment was conducted in a liquid bath mainly consisting of 2.5-10 g L ${ }^{-1}$ alkaline earth metal salt mixture $\left(\mathrm{Ca}\left(\mathrm{CH}_{3} \mathrm{COO}\right)_{2^{-}}\right.$ $\cdot \mathrm{H}_{2} \mathrm{O}$ and $\left.\mathrm{C}_{4} \mathrm{H}_{6} \mathrm{O}_{4} \mathrm{Mg} \cdot 4 \mathrm{H}_{2} \mathrm{O}\right), 10-19 \mathrm{~g} \mathrm{~L}^{-1}$ triethanolamine $\left(\mathrm{C}_{6} \mathrm{H}_{15} \mathrm{NO}_{3}\right)$, 0.25-1.0 $\mathrm{g} \mathrm{L}^{-1}$ sodium dodecyl diphenyl ether disulfonate $\left(\mathrm{C}_{24} \mathrm{H}_{32} \mathrm{O}_{7} \mathrm{~S}_{2} \mathrm{Na}_{2}\right)$, and $2 \mathrm{~g} \mathrm{~L}^{-1}$ ammonium acetate $\left(\mathrm{CH}_{3} \mathrm{COONH}_{4}\right)$. The solution adopted for electrochemical measurements was $3.5 \% \mathrm{NaCl}$.

\section{Optimization of the experimental parameters}

L16 $\left(4^{5}\right)$ orthogonal design was employed for obtaining the optimal hole sealing conditions, as shown in Table 1. Mixed alkaline earth metal salts in the hole sealing liquid was used at the ratio of the calcium salt to magnesium salt of $1: 4(\mathrm{w} / \mathrm{w})$. Auxiliary additives (see Table 1) were also adopted for optimization of the hole sealing, including complexant, surfactant, and $\mathrm{pH}$ buffer (at a constant concentration of $2 \mathrm{~g} \mathrm{~L}^{-1}$ ). The sealing rate and time were set to $0.5 \mu \mathrm{m} \mathrm{min}{ }^{-1}$ and 24-30 min, respectively. The sealing processing was performed on the anodically oxidized samples 1-16.

\section{Evaluation of the sealing quality}

Antistaining adsorption and weight loss tests were employed for evaluating the sealing quality. For the antistaining adsorption test, the prepared samples 1-16 were degreased, processed with acids, and stained with a blue colorant (with the international color no. of 69). The staining effect, i.e., the antistaining 
adsorption ability of the sealed AAO film, was evaluated based on the ISO2143:2010 standard. The ISO3210:2010 standard was used for conducting the weight loss test and hence for further evaluating the quality of the sealed AAO-based samples.

\section{Characterizations}

The EOECD-30A-type power source was adopted for anodization coloring of 6063 aluminum alloy samples. During the anodic oxidation, a conversion-type refrigerated freezer (BC/BD-143), an electric-heated thermostatic water bath, and a non-contact infrared thermometer $\left(\mathrm{AR} 842 \mathrm{~A}^{+}\right)$were employed for strictly controlling the temperature. The electrochemical measurements were performed on an electrochemical workstation (CS310) based on a three-electrode system, where the saturated calomel electrode (SCE) and platinum electrode worked as the reference and counter electrodes, respectively. The scanning range of the potentiodynamic polarization curve was set as -1.0 to $+0.5 \mathrm{~V}$, with the scanning rate and sampling interval as $1 \mathrm{mV}$ $\mathrm{s}^{-1}$ and $1 \mathrm{~s}$, respectively. The range of the alternating current (AC) impedance test rate was set as $10^{-2}-10^{5} \mathrm{~Hz}$, with the alternating current amplitude of the sinusoidal wave as $10 \mathrm{mV}$. The wide-band responses at the frequencies $>10$ and $<10$ were $470 \mathrm{pF}$ and $2.2 \mathrm{nF}$, respectively. The parameters including filter and earthing mode were set to $470 \mathrm{nF}$ and field, respectively. The microscopic morphologies of the prepared samples were observed on an S-480 Field emission scanning electron microscope (SEM, HITACHI). Fourier Transform Infrared Spectroscopy (FTIR) spectra were captured on an IRAffinity-1S spectrophotometer (Shimadzu).

\section{Conclusions}

The following conclusions can be drawn from this systematic study.

(1) Upon optimization of the hole sealing formulation based on the alkaline earth metal salt, the optimal experimental parameters are obtained: (i) the concentrations of the salt mixture, complexant, surfactant, and buffer are suggested to be $10,16,0.5$, and $2 \mathrm{~g} \mathrm{~L}^{-1}$, respectively; (ii) $\mathrm{pH}$, temperature and sealing time are suggested to be $7,85^{\circ} \mathrm{C}$, and $24-30 \mathrm{~min}$, respectively. Under given conditions, the order of the impact of various experimental conditions on the weight loss of the sealed samples is given as follows: temperature $>\mathrm{pH}>$ salt mixture $>$ surfactant $>$ complexant.

(2) The electrochemical measurement of the self-corrosion current density reveals a higher corrosion resistance of the alkaline earth metal salt-sealed sample as compared to the conventional nickel salt-sealed sample. Over all the EIS test regions, the electrical resistance of the porous layer of the alkaline earth metal salt-sealed sample is higher than that of the nickel salt-sealed sample.

(3) Through tracking the $E$ - $t$ curve during hole sealing, it has been noted that raising the temperature can more quickly stabilize the potential over the temperature range of $70-85{ }^{\circ} \mathrm{C}$. The higher $\mathrm{pH}$ value over the $\mathrm{pH}$ range of 5-7 make the potential more easily stabilized, while the potential cannot be stabilized at pHs larger than 7; the addition of surfactant, complexant, or buffer can help to quickly stabilize the potential, whereas the potential cannot be stabilized if without the addition of surfactant or complexant.

(4) This study has also discussed the mechanism underlying the effective hole sealing, with schematic illustration presented in Scheme 1.

\section{Conflicts of interest}

There are no conflicts to declare.

\section{Acknowledgements}

We greatly acknowledge the National Natural Science Foundation of China (No. 21671038), Special Funding Projects of the Technical Innovation of Foshan City (No. 2014AG10009, No. 2016AG100341), and Engineering Project for Innovation and for Enhancing Universities in Guangdong Province (No. 2016GCZX008).

\section{Notes and references}

1 (a) J. Lee, D. Kim, C.-H. Choi and W. Chung, Nano Energy, 2017, 31, 504-513; (b) M. C. Lafouresse, M.-L. de BonfilsLahovary, C. Charvillat, L. Oger, L. Laffont and C. Blanc, J. Alloys Compd., 2017, 722, 760-766; (c) T. Aerts, T. Dimogerontakis, I. De Graeve, J. Fransaer and H. Terryn, Surf. Coat. Technol., 2007, 201, 7310-7317; (d) A. Hakimizad, K. Raeissi and F. Ashrafizadeh, Surf. Coat. Technol., 2012, 206, 4628-4633; (e) V. Moutarlier, M. P. Gigandet, B. Normand and J. Pagetti, Corros. Sci., 2005, 47, 937-951; (f) C. A. Munson and G. M. Swain, Surf. Coat. Technol., 2017, 315, 150-162; (g) S. Mokhtari, F. Karimzadeh, M. H. Abbasi and K. Raeissi, Surf. Coat. Technol., 2017, 324, 99-105; (h) H. Wei, H. Hu, M. Chang, Y. Zhang, D. Chen and M. Wang, Ceram. Int., 2017, 43, 12472-12479; (i) Y. Zhang, H. Hu, M. Chang, H. Wei, D. Chen, M. Zhang, L. Wu and X. Li, J. Mater. Sci., 2018, 53, 2102-2114.

2 (a) M. Raoufi and H. Schönherr, RSC Adv., 2013, 3, 13429; (b) F. Zhang, J. Evertsson, F. Bertram, L. Rullik, F. Carla, M. Långberg, E. Lundgren and J. Pan, Electrochim. Acta, 2017, 241, 299-308; (c) M. Saeedikhani, M. Javidi and S. Vafakhah, Trans. Nonferrous Met. Soc. China, 2017, 27, 711-721; (d) X. Zhu, J. Fan, Y. Zhang, H. Zhu, B. Dai, M. Yan and Y. Ren, J. Mater. Sci., 2017, 52, 12717-12723.

3 (a) B. Jang, X.-Z. Chen, R. Siegfried, J. M. Montero Moreno, B. Özkale, K. Nielsch, B. J. Nelson and S. Pané, RSC Adv., 2015, 5, 94283-94289; (b) M. He, J. Yao, Z.-X. Low, D. Yu, Y. Feng and H. Wang, RSC Adv., 2014, 4, 7634; (c) J. Huo, H. Hu, M. Zhang, X. Hu, M. Chen, D. Chen, J. Liu, G. Xiao, Y. Wang and Z. Wen, RSC Adv., 2017, 7, 2281-2287; (d) S. M. H. Gardazi, T. A. Butt, N. Rashid, A. Pervez, Q. Mahmood, M. M. Shah and M. Bilal, Desalin. Water Treat., 2016, 57, 28981-28998; (e) Y. Huang, Y. Ma, H. Hu, 
P. Guo, L. Miao, Y. Yang and M. Zhang, RSC Adv., 2017, 7, 52091-52100.

4 (a) M. Hao, S. Wu, H. Zhou, W. Ye, X. Wei, X. Wang, Z. Chen and S. Li, J. Mater. Sci., 2015, 51, 2420-2426; (b) R. Senbahavalli, S. Mohanapriya and V. Raj, Materials Discovery, 2016, 3, 29-37.

5 Y. Wu, W. Zhao, W. Wang, L. Wang and Q. Xue, Sci. Rep., 2017, 7, 1344.

6 (a) Y. Shang, Int. J. Electrochem. Sci., 2016, 5234-5244, DOI: 10.20964/2016.06.85; (b) N. Hu, X. Dong, X. He, J. F. Browning and D. W. Schaefer, Corros. Sci., 2015, 97, 17-24; (c) S.-K. Hwang, S.-H. Jeong, O.-J. Lee and K.-H. Lee, Microelectron. Eng., 2005, 77, 2-7; (d) M. Chang, H. Wei, D. Chen, H. Hu, Y. Zhang, X. Ye, K. Zeng and D. Li, Nano Research \& Applications, 2017, 3, 1-8; (e) F. Zhang, M. Yan, J. He and F. Yin, Ceram. Int., 2017, 43, 10832-10839; $(f)$ J. J. Roa, B. Gastón-García, E. García-Lecina and C. Müller, Ceram. Int., 2012, 38, 1627-1633; (g) I. Mohammadi, A. Afshar and S. Ahmadi, Ceram. Int., 2016, 42, 1210512114; (h) M. N. Ibarra Castro, J. M. Almanza Robles, D. A. Cortés Hernandez, J. C. Escobedo Bocardo and J. Torres Torres, Ceram. Int., 2010, 36, 1205-1210; (i) B.-D. Hahn, Y. Kim, C.-W. Ahn, J.-J. Choi, J. Ryu, J.-W. Kim,
W.-H. Yoon, D.-S. Park, S.-Y. Yoon and B. Ma, Ceram. Int., 2016, 42, 18141-18147.

7 (a) C.-c. Jiang, Y.-k. Cao, G.-y. Xiao, R.-f. Zhu and Y.-p. Lu, RSC Adv., 2017, 7, 7531-7539; (b) X. Yu, C. Yan and C. Cao, Mater. Chem. Phys., 2002, 76, 228-235.

8 (a) B. Ramezanzadeh, H. Vakili and R. Amini, J. Ind. Eng. Chem., 2015, 30, 225-233; (b) H.-Y. Su and C.-S. Lin, Corros. Sci., 2014, 83, 137-146.

9 (a) H. Hu, J. H. Xin and H. Hu, J. Mater. Chem. A, 2014, 2, 11319; (b) H. Hu, M. Chang, M. Zhang, X. Wang and D. Chen, J. Mater. Sci., 2017, 52, 8650-8664; (c) H. Hu, M. Chang, X. Wang and D. Chen, J. Mater. Sci., 2017, 52, 9922-9930; (d) H. Hu, J. H. Xin, H. Hu and X. Wang, Nano Res., 2015, 8, 3992-4006; (e) H. Hu, C. C. K. Allan, J. Li, Y. Kong, X. Wang, J. H. Xin and H. Hu, Nano Res., 2014, 7, 418-433.

10 Y. Shi, B. Zhou, P. Wu, K. Wang and C. Cai, J. Electroanal. Chem., 2007, 611, 1-9.

11 (a) P. Ding and B. Qu, Mater. Lett., 2006, 60, 1233-1237; (b) J. García-Martínez, A. Bueno-López, A. García-García and A. Linares-Solano, Fuel, 2002, 81, 305-313; (c) H. Hu, X. Wang, D. Miao, Y. Wang, C. Lai, Y. Guo, W. Wang, J. H. Xin and H. Hu, Chem. Commun., 2015, 51, 16699-16702. 